\title{
Dendritic/Post-synaptic Tau and Early Pathology of Alzheimer's Disease
}

\author{
Xiaomin Yin 1,2,3, Chenhao Zhao' ${ }^{1}$, Yanyan Qiu' ${ }^{1}$, Zheng Zhou' ${ }^{1}$, Junze Bao ${ }^{1}$ and \\ Wei Qian ${ }^{1,2,3 *}$ \\ ${ }^{1}$ Department of Biochemistry and Molecular Biology, Medical School, Nantong University, Nantong, China, ${ }^{2}$ Jiangsu Key \\ Laboratory of Neuroregeneration of Jiangsu and Ministry of Education of China, Co-innovation Center of Neuroregeneration, \\ Nantong University, Nantong, China, ${ }^{3}$ NMPA Key Laboratory for Research and Evaluation of Tissue Engineering Technology \\ Products, Nantong University, Nantong, China
}

\section{OPEN ACCESS}

Edited by:

Michele Papa,

University of Campania Luigi Vanvitelli,

Reviewed by:

Hwan-Ching Tai,

National Taiwan University, Taiwan

Lidia Bakota,

University of Osnabrück, Germany

${ }^{*}$ Correspondence:

Wei Qian

weiqian@ntu.edu.cn

Received: 24 February 2021 Accepted: 27 May 2021

Published: 25 June 2021

Citation:

Yin X, Zhao C, Qiu Y, Zhou Z, Bao J and Qian W (2021)

Dendritic/Post-synaptic Tau and Early Pathology of Alzheimer's Disease. Front. Mol. Neurosci. 14:671779. doi: 10.3389/fnmol.2021.671779
Microtubule-associated protein tau forms insoluble neurofibrillary tangles (NFTs), which is one of the major histopathological hallmarks of Alzheimer's disease (AD). Many studies have demonstrated that tau causes early functional deficits prior to the formation of neurofibrillary aggregates. The redistribution of tau from axons to the somatodendritic compartment of neurons and dendritic spines causes synaptic impairment, and then leads to the loss of synaptic contacts that correlates better with cognitive deficits than amyloid- $\beta(A \beta)$ aggregates do in AD patients. In this review, we discuss the underlying mechanisms by which tau is mislocalized to dendritic spines and contributes to synaptic dysfunction in AD. We also discuss the synergistic effects of tau and oligomeric forms of $A \beta$ on promoting synaptic dysfunction in $A D$.

Keywords: tau, Alzheimer's disease, cognitive impairment, post-synapse, synaptic localization

\section{INTRODUCTION}

Tau is a microtubule-associated protein (MAP) that participates in microtubule assembly and stabilization (Weingarten et al., 1975; Drechsel et al., 1992). Tau protein has a very dynamic interaction with microtubules (Konzack et al., 2007). This highly dynamic interaction had been described as a kiss and hop mechanism with 40 ms dwell time (Igaev et al., 2014; Janning et al., 2014).

Tau is encoded by MAPT gene including 16 exons on chromosome 17q21 (Neve et al., 1986). Six molecular isoforms of tau are generated from alternative splicing of exons 2, 3, and 10 in MAPT gene transcripts in human brain (Amos, 2014). These six tau isoforms including three $3 \mathrm{R}$ taus $(0 \mathrm{~N} 3 \mathrm{R}, 1 \mathrm{~N} 3 \mathrm{R}$, and $2 \mathrm{~N} 3 \mathrm{R})$ and three $4 \mathrm{R}$ taus $(0 \mathrm{~N} 4 \mathrm{R}, 1 \mathrm{~N} 4 \mathrm{R}$, and $2 \mathrm{~N} 4 \mathrm{R})$, differ in containing three (3R taus) or four (4R taus) microtubule binding repeats (R) of 31-32 amino acids in the carboxyl terminal half and zero $(0 \mathrm{~N})$, one $(1 \mathrm{~N})$, or two $(2 \mathrm{~N})$ amino terminal inserts of 29 amino acids each (Iqbal et al., 2009). Tau is phosphorylated at serine/threonine sites or/and tyrosine sites, and the biological activity of tau is regulated by the degree of phosphorylation modification (Lindwall and Cole, 1984; Kopke et al., 1993; Alonso et al., 1994). All of the six tau isoforms are hyperphosphorylated and aggregated into neurofibrillary tangles (NFTs) in Alzheimer's disease (AD) brain (Grundke-Iqbal et al., 1986; Iqbal et al., 1986, 1989; Lee et al., 1991; Goedert et al., 1992). A disease-like pseudohyperphosphorylation of tau dramatically diminishes the taumicrotubules interaction (Niewidok et al., 2016). Interestingly, tau protein in the brain becomes 
highly phosphorylated during hibernation in different species, such as arctic ground squirrel, Syrian hamsters and black bears, and this hyperphosphorylation is reversed after arousal (Su et al., 2008; Stieler et al., 2011). To date, the majority research of tau pathology has been concentrated on the processes of tau aggregation and its subsequent toxicity to neurons. In this review, we focus on the mislocalization of tau from axons to dendrites and post-synapses. It is an earlier event in $\mathrm{AD}$ pathogenesis prior to the formation of amyloid plaques and NFTs and therefore may be a preferable therapeutic target.

\section{SYNAPTIC LOCALIZATION OF TAU}

\section{Tau Distribution Under Physiological Conditions}

Most of tau localizes in the distal segment of the axon, lower concentrations are found in the proximal segment of the axon, and the lowest levels in the soma and dendrites (Black et al., 1996; Mandell and Banker, 1996) (Figure 1). It is reported that approximately three times more tau exists in the white matter (mainly containing axons) than the gray matter (mainly containing dendrites and cell bodies) of rat and bovine brains (Binder et al., 1985). Studies also found endogenous tau localized in dendrites and post-synapses of rodent neurons (Ittner et al., 2010; Mondragon-Rodriguez et al., 2012b; Zempel et al., 2013; Kimura et al., 2014; Swanson et al., 2017). Endogenous murine tau was shown to localize to dendritic spines (Xia et al., 2016). Furthermore, physiological tau was observed both at presynaptic and postsynaptic termini in human brains (Tai et al., 2012). The post-synaptic localization of tau suggests that tau has physiological functions not only in the axon but also in the synapse (Ittner et al., 2010; Kimura et al., 2014; Regan et al., 2015). Tau plays roles in microtubule stabilization and axonal transport as an axonal cytoskeletal protein (Guo et al., 2017), whereas synaptic tau engages in neuronal signaling and synaptic plasticity (Ittner et al., 2010; Chen et al., 2012).

\section{Possible Mechanisms of Physiological Tau Distribution}

The underlying mechanisms responsible for the axonal tau gradient are in dispute. Evidence suggests several overlapping mechanisms. First, since the affinity of tau to axonal microtubules is higher than that of dendrites or soma in neurons, tau is predominantly localized to axons (Kanai and Hirokawa, 1995; Hirokawa et al., 1996). The axon initial segment (AIS) also provides a barrier limiting the amount of tau to relocate from axons to the soma ( $\mathrm{Li}$ et al., 2011). This retrograde diffusional restriction of tau may be governed by several proteinprotein interactions of tau with AIS complexes (such as ankyrin G/EB1, GSK3ß) (Zempel et al., 2017). Second, tau is selectively degraded in the somatodendritic compartment by autophagy and proteasomes. Third, the distribution of tau mRNA connects with native introns and untranslated regions UTR (Kanai and Hirokawa, 1995; Hoover et al., 2010).

\section{TAU BINDING PROTEINS IN THE POST-SYNAPSE}

Tau interacts with the Src family kinase Fyn via its Proline$\mathrm{X}$-X-Proline (PXXP) motifs in the Proline-rich region (Lee et al., 1998; Ittner et al., 2010; Lau et al., 2016). Fyn fails to localize to the synapse in tau-depleted neurons (Ittner et al., 2010; Sapir et al., 2012). The tau/Fyn complex binds to PSD-95 (post-synaptic density protein 95) at the postsynapse (Ittner et al., 2010; Mondragon-Rodriguez et al., 2012b; Lopes et al., 2016). PSD-95 is a key scaffolding protein for post-synaptic receptors (Kim and Sheng, 2004). The interaction between PSD-95 and NMDAR or AMPAR is primarily mediated by the postsynaptic density-95, diskslarge, zona occludens 1 (PDZ) domains (Christensen et al., 2019). Tau connects with PSD-95 as well as NMDARs or AMPARs, the post-synaptic receptors (Ittner and Ittner, 2018). Tau, Fyn, PSD-95, and NMDARs are predicted to form a protein complex at the synapse (Mondragon-Rodriguez et al., 2012b) (Figure 2A).

The localized activity of Fyn is critical for NMDAR-mediated excitotoxicity (Ittner et al., 2010; Knox et al., 2014; Miyamoto et al., 2017). Fyn phosphorylates the subunit 2B (NR2B) of NMDAR at tyrosine-1472 of cytosolic C-terminus, which promotes the interaction between NR2B and PSD-95 and results in toxic downstream signaling pathways in neurons (Rong et al., 2001). Decreased synaptic clustering of both NMDA and AMPA receptors is induced by the infiltration of tau into dendritic spines, thereby resulting in compromised excitatory synaptic transmission and memory deficits (Hoover et al., 2010; Xia et al., 2015; Kim et al., 2016; Yin et al., 2016; Zhao et al., 2016).

Tau interacts with microtubules and regulates their turnover to modulate the dynamic movement of microtubules into and out of dendritic spines, which is important to long-term depression (LTD) induction (Kapitein et al., 2011). Similarly, tau influences the cross-talk between microtubules and actin cytoskeletal networks through direct binding to actin (Fulga et al., 2007) or regulation of microtubule entry into spines (Jaworski et al., 2009), which is an important regulator of synaptic function and AMPAR trafficking (Zhou et al., 2001, 2004).

\section{ROLE OF TAU IN POST-SYNAPSE}

Tau in post-synapse is crucial for LTD (Kimura et al., 2014). Transfection of tau shRNA prevented the induction of LTD but not LTP. The necessary role of tau in the hippocampal LTD is supported by the rescued LTD phenotype when endogenous tau was replaced with human tau. The requirement for tau in hippocampal LTD is also verified by the selective deficits in spatial reversal learning observed in tau knockout mice (Regan et al., 2015).

Tau also appears to modulate LTP since exposure of neurons to tau inhibits hippocampal LTP in rat hippocampal synapses (Ondrejcak et al., 2018). Similarly, the LTP inhibition is dependent on tau because co-injection with an antibody against 


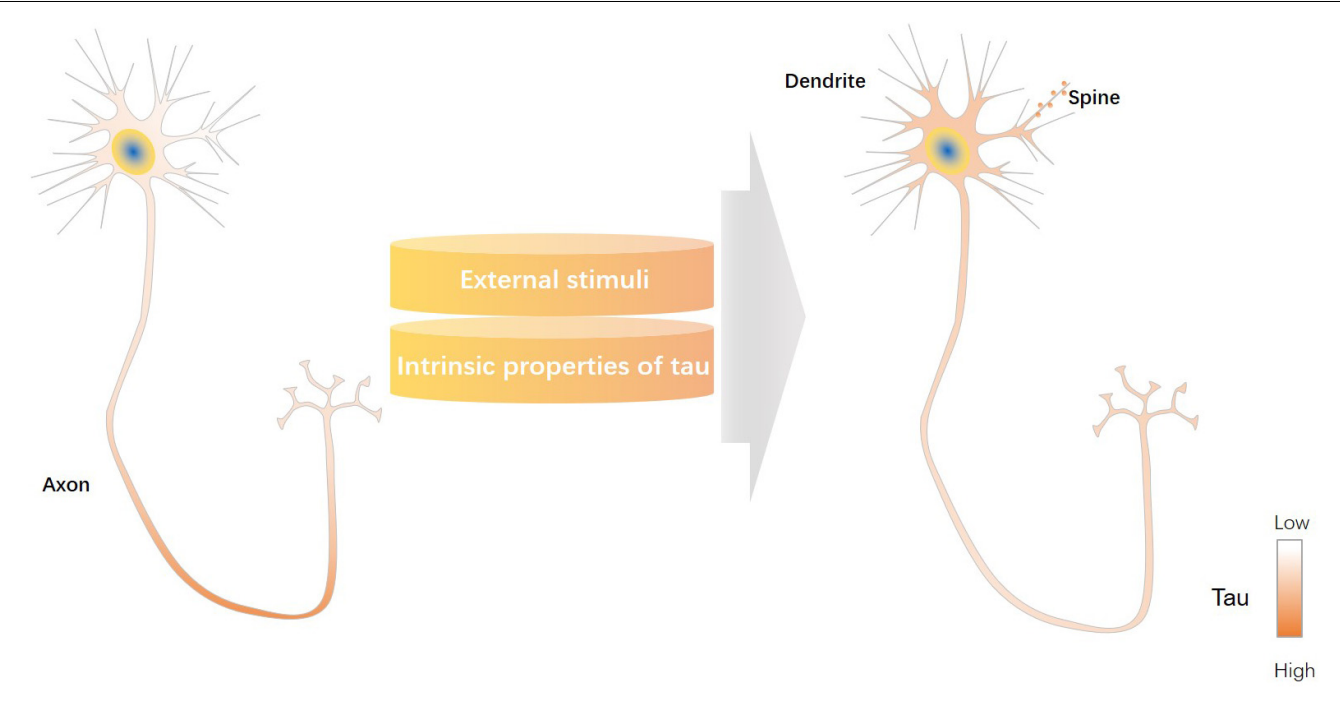

Tau distribution in neuron

FIGURE 1 | Regulatory factors involved in mislocalization of tau to dendrites/post-synapses. Under physiological conditions, most of tau is localized in the distal segment of the axon, whereas lower tau concentrations are found in the proximal segment of the axon, and the lowest levels in the soma and dendrites (left panel). External stimuli, including increased neuronal activity or treatment with amyloid-beta (A $\beta$ ) or glucocorticoids, can promote dendrite/post-synaptic localization of tau, while intrinsic properties of tau, such as those caused by altered tau splicing, truncations, phosphorylation and acetylation modifications, affect the dendrite/post-synaptic translocation of tau (middle panel). Tau redistributes to the somatodendritic compartment and post-synapses under pathological conditions (right panel).

tau can prevent the LTP inhibition caused by extracts of Alzheimer's disease brain (Ondrejcak et al., 2018).

It has been identified that tau plays an important physiological role in synapses by studies using tau knockout mice (Ke et al., 2012; Ahmed et al., 2014; Biundo et al., 2018). Further investigations are still required to detect the physiological roles of tau in synapses. Tau acts as a mediator of AD-related synaptic deficits, which has been demonstrated by numerous studies (Spires-Jones and Hyman, 2014). The increased concentration of tau in dendrites may affected memory and synaptic plasticity. Mislocalized tau reduces the miniature excitatory postsynaptic currents (mEPSCs) in rats. A silencing of synapses and reduction of AMPARs in the post synaptic site accompany a decrease in mEPSCs (Hoover et al., 2010). Dendritic tau is mostly hyperphosphorylated (Brion et al., 1994; Gotz et al., 1995; Tashiro et al., 1997; Ittner et al., 2010; Shentu et al., 2018), dissociated from microtubules and related to dendritic spine loss (Thies and Mandelkow, 2007). Dendritic tau is involved in dendritic loss, aberrant post-synaptic activity and cognitive dysfunction in AD or other tauopathies (Hoover et al., 2010; Zhao et al., 2016; Bories et al., 2017). Overexpression of tau in cultured neurons and $\mathrm{AD}$ mice increases tau in the somatodendritic compartment (Zempel et al., 2017). Importantly, the increased postsynaptic tau was linked to spine loss in a tau transgenic mouse model (Zempel et al., 2017; Ittner and Ittner, 2018). Synaptic loss is the earliest indication of neuronal malfunction and the best biological correlate of disease progression in $\mathrm{AD}$ and related tauopathies (Masliah et al., 1991; Terry et al., 1991; Scheff et al., 2006). Under pathological conditions, such as in human tauopathy or animal models of tau overexpression, the presence of tau at synapses is more apparent, suggesting a role for tau in disease pathogenesis (Hoover et al., 2010; Ittner et al., 2010; Pooler et al., 2014; Sokolow et al., 2015; Dejanovic et al., 2018; Ji et al., 2019; Kubo et al., 2019).

\section{EXTERNAL STIMULI LEADING TO POST-SYNAPTIC DISTRIBUTION OF TAU}

Neuronal activity and extracellular signals regulate dendritic/post-synaptic localization of tau. Increased neuronal activity or treatment with amyloid-beta $(A \beta)$ or glucocorticoids can increase the dendritic and synaptic localization of tau (Frandemiche et al., 2014; Pinheiro et al., 2016). Long-term potentiation (LTP), a synaptic plasticity mechanism critical for memory formation (Bannerman et al., 2014), can increase postsynaptic levels of tau (Frandemiche et al., 2014). Engagement and redistribution of post-synaptic glutamate receptors is critical to synaptic plasticity (Paoletti et al., 2013). In cultured neurons, activation of post-synaptic glutamate receptors induces translocation of tau from dendritic shafts into postsynaptic densities (Ittner et al., 2010; Frandemiche et al., 2014). Glucocorticoid treatment leads tau localization to soma and dendrites (Sotiropoulos et al., 2011; Lopes et al., 2016). Exposure to oligomeric $\mathrm{A} \beta$ increases levels of tau in dendrites in $\mathrm{AD}$ (Zempel et al., 2010). In general, external stimuli regulate dendritic localization of tau (Figure 1). 
A

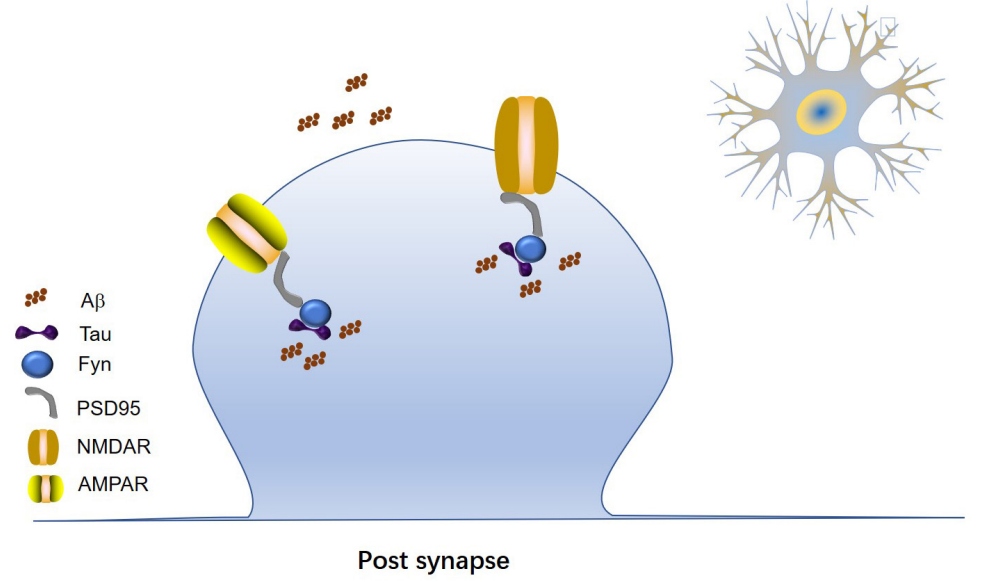

B

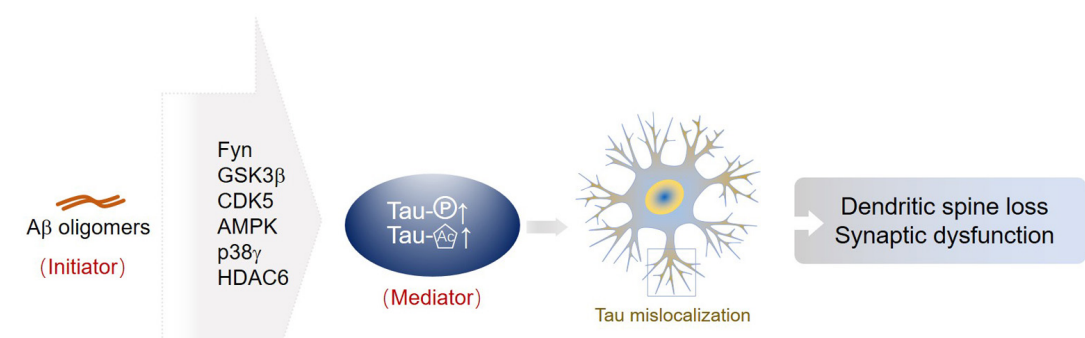

FIGURE 2 | Tau associated proteins in post-synapses. (A) Tau-Fyn-PSD95-post-synaptic receptor complex in the post-synaptic compartment. Tau, Fyn, PSD-95, and NMDARs or AMPARs are predicted to form a protein complex at the synapse. (B) A $\beta$ oligomers are an initiator of synaptic dysfunction, and synaptic tau seems to be an indispensable mediator in the progress. Fyn is the mediator between $A \beta$ and tau. GSK3 $\beta$ may be a central factor linking extracellular $A \beta$ and intracellular tau. $A \beta$ may activate $C D K 5$ to phosphorylate tau at synaptic sites. AMPK and p38 $\gamma$ may take part in tau phosphorylation induced by A $\beta$, but subsequently they have opposite effects on synaptic function. A $\beta$ inhibits activity of HDAC6 and increases acetylation levels of tau, resulting in loss of tau polarization.

\section{INTRINSIC PROPERTIES OF TAU RELATED TO POST-SYNAPTIC LOCATION}

\section{Isoforms of Tau}

Different tau isoforms may contribute to their dendritic and post-synaptic recruitment. $2 \mathrm{~N}$ tau is prone to sorting into the somatodendritic compartment, compared to other tau isoforms (Zempel et al., 2017). Whether 3R and $4 \mathrm{R}$ tau isoforms are differentially localized to dendrites/post-synapses remains elusive (Ittner and Ittner, 2018).

\section{Truncations of Tau}

Caspase-2 cleaves tau at Asp314 to generate $\triangle$ tau314, which is necessary for tau to mislocalize to dendritic spines (Zhao et al., 2016). In addition, the caspase-3 cleavage of tau at Asp421 may contribute to tau synaptic propagation in neurons (Kim et al., 2016; Nicholls et al., 2017). Several lines of evidence suggest that truncated forms of tau may also contribute to synaptic dysfunction. Mutating Asp314 on tau to prevent the caspase-2 cleavage of human P301L tau blocks mislocalization of tau to the dendritic compartment and prevents cognitive impairment in AD mouse models (Zhao et al., 2016). Normal memory and dendritic spine morphology are exhibited in J20 APP transgenic mice lacking caspase-2 (Pozueta et al., 2013).

\section{Post-translational Modifications of Tau}

Tau undergoes several post-translational modifications (PTMs), including phosphorylation, acetylation, ubiquitination, methylation, and glycosylation (Morris et al., 2015).

Tau has more than 45 phosphorylation sites mainly located in its proline-rich domain and C-terminal domain (MondragonRodriguez et al., 2008a,b, 2012a,b, 2014; Regan et al., 2015). Phosphorylation of tau directly affects the distribution of tau to dendrite and post-synapse. Individual phosphorylationmimicking tau mutants at T231/S235, S262/S356, or S396/S404 enhances localization of tau into dendritic spines in cultured neurons (Xia et al., 2015). Phosphorylation-mimicking tau with 14 simultaneous mutant sites induces tau to dendritic spines in cultured neurons, then reduces AMPA receptors and finally leads to synaptic impairments (Hoover et al., 2010; Miller et al., 2014). Furthermore, increased tau phosphorylation causes mislocalization of tau to post-synaptic sites both in $\mathrm{AD}$ brain and in transgenic mice overexpressing P301S tau (Tai et al., 2012; Dejanovic et al., 2018). A series of studies indicate that one of the 
potential mechanisms responsible for post-synaptic localization of tau may be the association of tau with the tyrosine kinase Fyn. Increasing phosphorylation level of tau at sites such as Ser396, Ser404, Thr205, Thr231, and Ser235 promotes dissociation of the Tau/Fyn/PSD95 complex, which is crucial for LTD induction (Mondragon-Rodriguez et al., 2012a,b). In the same regard, phosphorylation of tau at Ser396 is necessary for the expression of hippocampal LTD (Regan et al., 2015). Non-phosphorylated tau contributes to LTP, while phosphorylated tau contributes to LTD (Shipton et al., 2011; Mondragon-Rodriguez et al., 2012a,b; Regan et al., 2015; Ittner et al., 2016). Tau phosphorylation, induced by the Pro301 to Leu301 mutation linked to FTDP-17, also weakens the AIS barrier by structurally modifying the AIS and shifting its location (Hatch et al., 2017).

Bovine tau is modified by O-GlcNAcylation, a unique type of O-glycosylation for cytosolic proteins (Arnold et al., 1996). Human brain tau is also O-GlcNAcylated, and O-GlcNAcylation regulates phosphorylation of tau in a site-specific manner (Liu et al., 2004). Reduced O-GlcNAcylation of tau results in hyperphosphorylation of tau (Gong et al., 2006; Deng et al., 2009). $O-G l c N A c y l a t i o n$ of tau prevents tau from oligomerization and decreases neuronal cell loss (Yuzwa et al., 2012).

Acetylation of tau in post-synapse participates in an activitydependent pathway regulating synaptic plasticity and memory. Acetylation-mimicking tau mutants reduce Kidney/Brain (KIBRA) protein, a known regulator of AMPARs and memory (Makuch et al., 2011), and AMPAR presentation, and impairs hippocampal LTP (Tracy et al., 2016). This impairment affects memory and is associated with AD (Forner et al., 2017). Acetylated tau reduces KIBRA and impairs LTP by impeding activity-induced actin polymerization and thereby affecting postsynaptic membrane localization of AMPA receptors, which implicates the vital function of tau in regulating synaptic plasticity (Tracy and Gan, 2017). Acetylation of tau destabilizes the AIS, weakens the barrier, and allows retrograde redistribution of tau into the somatodendrites (Sohn et al., 2016).

\section{TAU AND A $\beta$}

Amyloid- $\beta$ may initiate mislocalization of tau at dendrites, which in turn can affect accumulation of $A \beta$. Oligomerized $\mathrm{A} \beta$ can only increase mislocalization of tau to the dendrites when tau is phosphorylated (Miller et al., 2014). Fyn is the mediator between $A \beta$ and tau. $A \beta$ promotes the post-synaptic localization of tau, and then the increased concentration of tau attracts Fyn to phosphorylate and activate NMDA receptor and triggers excitotoxicity due to calcium dyshomeostasis (Ittner et al., 2010). It has been reported that decreasing tau levels in $\mathrm{A} \beta$-forming $\mathrm{AD}$ mouse models prevented the post-synaptic dysfunction (Roberson et al., 2007, 2011; Ittner et al., 2010; Bi et al., 2017). In contrast, increasing tau levels in amyloidosis mouse models enhanced synaptic loss and memory impairment (Ittner et al., 2010; Chabrier et al., 2014). Tau phosphorylation contributes to dendritic spine loss (Mairet-Coello et al., 2013) and neuronal death (Tackenberg et al., 2013) induced by $A \beta$. Colocalization of $\mathrm{A} \beta$ and tau is shown in approximately one third of synapses in AD brain (Fein et al., 2008) (Figure 2A). GSK3 $\beta$ may be the central factor linking extracellular $A \beta$ and intracellular tau (Mandelkow, 1999; Dewachter et al., 2009), since $\mathrm{A} \beta$ can increase phosphorylated tau while GSK3 $\beta$ inhibition can block the increasing of phosphorylated tau and prevent $\mathrm{A} \beta$-induced impairment of LTP in mice (Shipton et al., 2011). Deregulation of Cdk5 caused by the accumulation of $\mathrm{p} 25$, a truncated fragment of $\mathrm{p} 35$, contributes to the pathogenesis of AD. The p25/Cdk5 kinase phosphorylates tau efficiently and hinders tau from binding to microtubules (Patrick et al., 1999). Proteomics data suggest that misfolded $A \beta$ may activate CDK5 to phosphorylate tau at synaptic sites (Wu et al., 2018). Eliminating the specific AMPK phosphorylation of tau prevents the $A \beta$ induced loss of dendritic spines and restores synaptic functions (Mairet-Coello et al., 2013; Zempel et al., 2013). On the contrary, post-synaptic p38 $\gamma$-mediated tau phosphorylation alleviates $A \beta$ induced excitotoxicity, suggesting the protective function of tau phosphorylation in the post-synaptic compartment (Ittner et al., 2016). Oligomeric A $\beta$ was shown to inhibit activity of histone deacetylase 6 (HDAC6) and increase acetylation levels of tau, resulting in loss of tau polarization (Tsushima et al., 2015).

\section{CONCLUSION}

In the present review, we discuss somatodendritic and postsynaptic localizations of tau under both physiological and pathological conditions. Mislocalization of tau to dendrites and post-synapses triggered by external and intrinsic factors is an early event in AD pathogenesis before tau aggregation (Figure 1). Synaptic tau, a mediator of AD-related synaptic deficits, associates with the onset of cognitive decline in AD. Synaptic impairments take place much earlier in $\mathrm{AD}$ pathogenesis than the formation of NFTs. Synaptic loss is highly correlated with cognitive decline and is the first indicator of $\mathrm{AD}$ progress. Abnormal PTMs of tau, such as phosphorylation, acetylation, and truncation, can all contribute to its mislocalization at synaptic sites. $\mathrm{A} \beta$ and tau drive synaptic dysfunction synergistically, which is the latent initial crisis in AD (Figure 2B). Therefore, therapeutic strategies targeting synaptic tau might be promising in intervening early pathological events in $\mathrm{AD}$.

\section{AUTHOR CONTRIBUTIONS}

WQ wrote the draft of the manuscript. All authors contributed to the manuscript revisions, as well as read and approved the submitted version.

\section{FUNDING}

This work was supported in part by Nantong University, the Priority Academic Program Development of Jiangsu Higher Education Institution (PAPD) and grants from the National Natural Science Foundation of China (81872875, 81170317, and 81473218 to WQ; 81503077 to XY). 


\section{REFERENCES}

Ahmed, T., Van der Jeugd, A., Blum, D., Galas, M. C., D’Hooge, R., Buee, L., et al. (2014). Cognition and hippocampal synaptic plasticity in mice with a homozygous tau deletion. Neurobiol. Aging 3511, 2474-2478. doi: 10.1016/j. neurobiolaging.2014.05.005

Alonso, A. C., Zaidi, T., Grundke-Iqbal, I., and Iqbal, K. (1994). Role of abnormally phosphorylated tau in the breakdown of microtubules in Alzheimer disease. Proc. Natl. Acad. Sci. U.S.A. 9112, 5562-5566. doi: $10.1073 /$ pnas.91.12.5562

Amos, L. A. (2014). Why do brains need tau (MAPT)? FEBS J. 28121, iv-v.

Arnold, C. S., Johnson, G. V., Cole, R. N., Dong, D. L., Lee, M., and Hart, G. W. (1996). The microtubule-associated protein tau is extensively modified with O-linked N-acetylglucosamine. J. Biol. Chem. 27146, 28741-28744. doi: 10. 1074/jbc.271.46.28741

Bannerman, D. M., Sprengel, R., Sanderson, D. J., McHugh, S. B., Rawlins, J. N., Monyer, H., et al. (2014). Hippocampal synaptic plasticity, spatial memory and anxiety. Nat. Rev. Neurosci. 153, 181-192.

Bi, M., Gladbach, A., van Eersel, J., Ittner, A., Przybyla, M., van Hummel, A., et al. (2017). Tau exacerbates excitotoxic brain damage in an animal model of stroke. Nat. Commun. 81:473.

Binder, L. I., Frankfurter, A., and Rebhun, L. I. (1985). The distribution of tau in the mammalian central nervous system. J. Cell Biol. 1014, 1371-1378. doi: 10.1083/jcb.101.4.1371

Biundo, F., Del Prete, D., Zhang, H., Arancio, O., and D’Adamio, L. (2018). A role for tau in learning, memory and synaptic plasticity. Sci. Rep. 81:3184.

Black, M. M., Slaughter, T., Moshiach, S., Obrocka, M., and Fischer, I. (1996). Tau is enriched on dynamic microtubules in the distal region of growing axons. J. Neurosci. 1611, 3601-3619. doi: 10.1523/jneurosci.16-11-03601.1996

Bories, C., Arsenault, D., Lemire, M., Tremblay, C., De Koninck, Y., and Calon, F. (2017). Transgenic autoinhibition of p21-activated kinase exacerbates synaptic impairments and fronto-dependent behavioral deficits in an animal model of Alzheimer's disease. Aging (Albany NY) 95, 1386-1403. doi: 10.18632/aging. 101239

Brion, J. P., Octave, J. N., and Couck, A. M. (1994). Distribution of the phosphorylated microtubule-associated protein tau in developing cortical neurons. Neuroscience 633, 895-909. doi: 10.1016/0306-4522(94)90533-9

Chabrier, M. A., Cheng, D., Castello, N. A., Green, K. N., and LaFerla, F. M. (2014). Synergistic effects of amyloid-beta and wild-type human tau on dendritic spine loss in a floxed double transgenic model of Alzheimer's disease. Neurobiol. Dis. 64, 107-117. doi: 10.1016/j.nbd.2014.01.007

Chen, Q., Zhou, Z., Zhang, L., Wang, Y., Zhang, Y. W., Zhong, M., et al. (2012). Tau protein is involved in morphological plasticity in hippocampal neurons in response to BDNF. Neurochem. Int. 603, 233-242. doi: 10.1016/j.neuint.2011. 12.013

Christensen, N. R., Calyseva, J., Fernandes, E. F. A., Luchow, S., Clemmensen, L. S., Haugaard-Kedstrom, L. M., et al. (2019). PDZ domains as drug targets. $A d v$. Ther. (Weinh) 27:1800143. doi: 10.1002/adtp.201800143

Dejanovic, B., Huntley, M. A., De Maziere, A., Meilandt, W. J., Wu, T., Srinivasan, K., et al. (2018). Changes in the synaptic proteome in tauopathy and rescue of tau-induced synapse loss by $\mathrm{Clq}$ antibodies. Neuron 1006, 1322-1336 e1327.

Deng, Y., Li, B., Liu, Y., Iqbal, K., Grundke-Iqbal, I., and Gong, C. X. (2009). Dysregulation of insulin signaling, glucose transporters, O-GlcNAcylation, and phosphorylation of tau and neurofilaments in the brain: implication for Alzheimer's disease. Am. J. Pathol. 1755, 2089-2098. doi: 10.2353/ajpath.2009. 090157

Dewachter, I., Ris, L., Jaworski, T., Seymour, C. M., Kremer, A., Borghgraef, P., et al. (2009). GSK3beta, a centre-staged kinase in neuropsychiatric disorders, modulates long term memory by inhibitory phosphorylation at serine- 9 . Neurobiol. Dis. 352, 193-200. doi: 10.1016/j.nbd.2009.04.003

Drechsel, D. N., Hyman, A. A., Cobb, M. H., and Kirschner, M. W. (1992). Modulation of the dynamic instability of tubulin assembly by the microtubuleassociated protein tau. Mol. Biol. Cell 310, 1141-1154. doi: 10.1091/mbc.3.10. 1141
Fein, J. A., Sokolow, S., Miller, C. A., Vinters, H. V., Yang, F., Cole, G. M., et al. (2008). Co-localization of amyloid beta and tau pathology in Alzheimer's disease synaptosomes. Am. J. Pathol. 1726, 1683-1692. doi: 10.2353/ajpath. 2008.070829

Forner, S., Baglietto-Vargas, D., Martini, A. C., Trujillo-Estrada, L., and LaFerla, F. M. (2017). Synaptic Impairment in Alzheimer's Disease: a dysregulated symphony. Trends Neurosci. 406, 347-357. doi: 10.1016/j.tins.2017.04.002

Frandemiche, M. L., De Seranno, S., Rush, T., Borel, E., Elie, A., Arnal, I., et al. (2014). Activity-dependent tau protein translocation to excitatory synapse is disrupted by exposure to amyloid-beta oligomers. J. Neurosci. 3417, 6084-6097. doi: 10.1523/jneurosci.4261-13.2014

Fulga, T. A., Elson-Schwab, I., Khurana, V., Steinhilb, M. L., Spires, T. L., Hyman, B. T., et al. (2007). Abnormal bundling and accumulation of F-actin mediates tau-induced neuronal degeneration in vivo. Nat. Cell Biol. 92, 139-148. doi: $10.1038 /$ ncb1528

Goedert, M., Spillantini, M. G., Cairns, N. J., and Crowther, R. A. (1992). Tau proteins of Alzheimer paired helical filaments: abnormal phosphorylation of all six brain isoforms. Neuron 81, 159-168. doi: 10.1016/0896-6273(92)90117-v

Gong, C. X., Liu, F., Grundke-Iqbal, I., and Iqbal, K. (2006). Impaired brain glucose metabolism leads to Alzheimer neurofibrillary degeneration through a decrease in tau O-GlcNAcylation. J. Alzheimers Dis. 91, 1-12. doi: 10.3233/jad-20069101

Gotz, J., Probst, A., Spillantini, M. G., Schafer, T., Jakes, R., Burki, K., et al. (1995). Somatodendritic localization and hyperphosphorylation of tau protein in transgenic mice expressing the longest human brain tau isoform. EMBO J. 147, 1304-1313. doi: 10.1002/j.1460-2075.1995.tb07116.x

Grundke-Iqbal, I., Iqbal, K., Quinlan, M., Tung, Y. C., Zaidi, M. S., and Wisniewski, H. M. (1986). Microtubule-associated protein tau. A component of Alzheimer paired helical filaments. J. Biol. Chem. 26113, 6084-6089.

Guo, T., Noble, W., and Hanger, D. P. (2017). Roles of tau protein in health and disease. Acta Neuropathol. 1335, 665-704. doi: 10.1007/s00401-017-1707-9

Hatch, R. J., Wei, Y., Xia, D., and Gotz, J. (2017). Hyperphosphorylated tau causes reduced hippocampal CA1 excitability by relocating the axon initial segment. Acta Neuropathol. 1335, 717-730. doi: 10.1007/s00401-017-1674-1

Hirokawa, N., Funakoshi, T., Sato-Harada, R., and Kanai, Y. (1996). Selective stabilization of tau in axons and microtubule-associated protein $2 \mathrm{C}$ in cell bodies and dendrites contributes to polarized localization of cytoskeletal proteins in mature neurons. J. Cell Biol. 1324, 667-679. doi: 10.1083/jcb.132. 4.667

Hoover, B. R., Reed, M. N., Su, J., Penrod, R. D., Kotilinek, L. A., Grant, M. K., et al. (2010). Tau mislocalization to dendritic spines mediates synaptic dysfunction independently of neurodegeneration. Neuron 686, 1067-1081. doi: 10.1016/j. neuron.2010.11.030

Igaev, M., Janning, D., Sundermann, F., Niewidok, B., Brandt, R., and Junge, W. (2014). A refined reaction-diffusion model of tau-microtubule dynamics and its application in FDAP analysis. Biophys. J. 10711, 2567-2578. doi: 10.1016/j. bpj.2014.09.016

Iqbal, K., Grundke-Iqbal, I., Smith, A. J., George, L., Tung, Y. C., and Zaidi, T. (1989). Identification and localization of a tau peptide to paired helical filaments of Alzheimer disease. Proc. Natl. Acad. Sci. U.S.A. 8614, 5646-5650. doi: 10.1073/pnas.86.14.5646

Iqbal, K., Grundke-Iqbal, I., Zaidi, T., Merz, P. A., Wen, G. Y., Shaikh, S. S., et al. (1986). Defective brain microtubule assembly in Alzheimer's disease. Lancet 28504, 421-426. doi: 10.1016/s0140-6736(86)92134-3

Iqbal, K., Liu, F., Gong, C. X., Alonso Adel, C., and Grundke-Iqbal, I. (2009). Mechanisms of tau-induced neurodegeneration. Acta Neuropathol. 1181, 5369. doi: 10.1007/s00401-009-0486-3

Ittner, A., Chua, S. W., Bertz, J., Volkerling, A., van der Hoven, J., Gladbach, A., et al. (2016). Site-specific phosphorylation of tau inhibits amyloid-beta toxicity in Alzheimer's mice. Science 3546314, 904-908. doi: 10.1126/science.aah6205

Ittner, A., and Ittner, L. M. (2018). Dendritic tau in Alzheimer's Disease. Neuron $991,13-27$.

Ittner, L. M., Ke, Y. D., Delerue, F., Bi, M., Gladbach, A., van Eersel, J., et al. (2010). Dendritic function of tau mediates amyloid-beta toxicity in Alzheimer's disease mouse models. Cell 1423, 387-397. doi: 10.1016/j.cell.2010.06.036 
Janning, D., Igaev, M., Sundermann, F., Bruhmann, J., Beutel, O., Heinisch, J. J., et al. (2014). Single-molecule tracking of tau reveals fast kiss-and-hop interaction with microtubules in living neurons. Mol. Biol. Cell 2522, 35413551. doi: 10.1091/mbc.e14-06- 1099

Jaworski, J., Kapitein, L. C., Gouveia, S. M., Dortland, B. R., Wulf, P. S., Grigoriev, I., et al. (2009). Dynamic microtubules regulate dendritic spine morphology and synaptic plasticity. Neuron 611, 85-100. doi: 10.1016/j.neuron.2008.11.013

Ji, C., Tang, M., Zeidler, C., Hohfeld, J., and Johnson, G. V. (2019). BAG3 and SYNPO (synaptopodin) facilitate phospho-MAPT/Tau degradation via autophagy in neuronal processes. Autophagy 157, 1199-1213. doi: 10.1080/ 15548627.2019 .1580096

Kanai, Y., and Hirokawa, N. (1995). Sorting mechanisms of tau and MAP2 in neurons: suppressed axonal transit of MAP2 and locally regulated microtubule binding. Neuron 142, 421-432. doi: 10.1016/0896-6273(95)90298-8

Kapitein, L. C., Yau, K. W., Gouveia, S. M., van der Zwan, W. A., Wulf, P. S., Keijzer, N., et al. (2011). NMDA receptor activation suppresses microtubule growth and spine entry. J. Neurosci. 3122, 8194-8209. doi: 10.1523/jneurosci.6215-10.2011

Ke, Y. D., Suchowerska, A. K., van der Hoven, J., De Silva, D. M., Wu, C. W., van Eersel, J., et al. (2012). Lessons from tau-deficient mice. Int. J. Alzheimers Dis. 2012,873270 .

Kim, E., and Sheng, M. (2004). PDZ domain proteins of synapses. Nat. Rev. Neurosci. 510, 771-781. doi: 10.1038/nrn1517

Kim, Y., Choi, H., Lee, W., Park, H., Kam, T. I., Hong, S. H., et al. (2016). Caspasecleaved tau exhibits rapid memory impairment associated with tau oligomers in a transgenic mouse model. Neurobiol. Dis. 87, 19-28. doi: 10.1016/j.nbd.2015. 12.006

Kimura, T., Whitcomb, D. J., Jo, J., Regan, P., Piers, T., Heo, S., et al. (2014). Microtubule-associated protein tau is essential for long-term depression in the hippocampus. Philos. Trans. R. Soc. Lond. B Biol. Sci. 3691633:20130144. doi: 10.1098/rstb.2013.0144

Knox, R., Brennan-Minnella, A. M., Lu, F., Yang, D., Nakazawa, T., Yamamoto, T., et al. (2014). NR2B phosphorylation at tyrosine 1472 contributes to brain injury in a rodent model of neonatal hypoxia-ischemia. Stroke 4510, 3040-3047. doi: $10.1161 /$ strokeaha.114.006170

Konzack, S., Thies, E., Marx, A., Mandelkow, E. M., and Mandelkow, E. (2007). Swimming against the tide: mobility of the microtubuleassociated protein tau in neurons. J. Neurosci. 2737, 9916-9927. doi: 10.1523/jneurosci.0927-07.2007

Kopke, E., Tung, Y. C., Shaikh, S., Alonso, A. C., Iqbal, K., and Grundke-Iqbal, I. (1993). Microtubule-associated protein tau. Abnormal phosphorylation of a non-paired helical filament pool in Alzheimer disease. J. Biol. Chem. 26832, 24374-24384. doi: 10.1016/s0021-9258(20)80536-5

Kubo, A., Misonou, H., Matsuyama, M., Nomori, A., Wada-Kakuda, S., Takashima, A., et al. (2019). Distribution of endogenous normal tau in the mouse brain. J. Comp. Neurol. 5275, 985-998. doi: $10.1002 /$ cne. 24577

Lau, D. H., Hogseth, M., Phillips, E. C., O’Neill, M. J., Pooler, A. M., Noble, W., et al. (2016). Critical residues involved in tau binding to fyn: implications for tau phosphorylation in Alzheimer's disease. Acta Neuropathol. Commun. 41:49.

Lee, G., Newman, S. T., Gard, D. L., Band, H., and Panchamoorthy, G. (1998). Tau interacts with src-family non-receptor tyrosine kinases. J. Cell Sci. 111 (Pt 21), 3167-3177. doi: $10.1242 /$ jcs.111.21.3167

Lee, V. M., Balin, B. J., Otvos, L. Jr., and Trojanowski, J. Q. (1991). A68: a major subunit of paired helical filaments and derivatized forms of normal Tau. Science 2514994, 675-678. doi: 10.1126/science. 1899488

Li, X., Kumar, Y., Zempel, H., Mandelkow, E. M., Biernat, J., and Mandelkow, E. (2011). Novel diffusion barrier for axonal retention of Tau in neurons and its failure in neurodegeneration. EMBO J. 3023, 4825-4837. doi: 10.1038/emboj. 2011.376

Lindwall, G., and Cole, R. D. (1984). Phosphorylation affects the ability of tau protein to promote microtubule assembly. J. Biol. Chem. 2598, 5301-5305. doi: 10.1016/s0021-9258(17)42989-9

Liu, F., Iqbal, K., Grundke-Iqbal, I., Hart, G. W., and Gong, C. X. (2004). OGlcNAcylation regulates phosphorylation of tau: a mechanism involved in Alzheimer's disease. Proc. Natl. Acad. Sci. U.S.A. 10129, 10804-10809. doi: 10.1073/pnas.0400348101
Lopes, S., Vaz-Silva, J., Pinto, V., Dalla, C., Kokras, N., Bedenk, B., et al. (2016). Tau protein is essential for stress-induced brain pathology. Proc. Natl. Acad. Sci. U.S.A. 11326, E3755-E3763.

Mairet-Coello, G., Courchet, J., Pieraut, S., Courchet, V., Maximov, A., and Polleux, F. (2013). The CAMKK2-AMPK kinase pathway mediates the synaptotoxic effects of Abeta oligomers through Tau phosphorylation. Neuron 781, 94-108. doi: 10.1016/j.neuron.2013.02.003

Makuch, L., Volk, L., Anggono, V., Johnson, R. C., Yu, Y., Duning, K., et al. (2011). Regulation of AMPA receptor function by the human memory-associated gene KIBRA. Neuron 716, 1022-1029. doi: 10.1016/j.neuron.2011.08.017

Mandelkow, E. (1999). Alzheimer's disease. The tangled tale of tau. Nature 4026762, 588-589. doi: $10.1038 / 45095$

Mandell, J. W., and Banker, G. A. (1996). A spatial gradient of tau protein phosphorylation in nascent axons. J. Neurosci. 1618, 5727-5740. doi: 10.1523/ jneurosci.16-18-05727.1996

Masliah, E., Hansen, L., Albright, T., Mallory, M., and Terry, R. D. (1991). Immunoelectron microscopic study of synaptic pathology in Alzheimer's disease. Acta Neuropathol. 814, 428-433. doi: $10.1007 / \mathrm{bf} 00293464$

Miller, E. C., Teravskis, P. J., Dummer, B. W., Zhao, X., Huganir, R. L., and Liao, D. (2014). Tau phosphorylation and tau mislocalization mediate soluble Abeta oligomer-induced AMPA glutamate receptor signaling deficits. Eur. J. Neurosci. 397, 1214-1224. doi: 10.1111/ejn.12507

Miyamoto, T., Stein, L., Thomas, R., Djukic, B., Taneja, P., Knox, J., et al. (2017). Phosphorylation of tau at Y18, but not tau-fyn binding, is required for tau to modulate NMDA receptor-dependent excitotoxicity in primary neuronal culture. Mol. Neurodegener. 121:41.

Mondragon-Rodriguez, S., Basurto-Islas, G., Santa-Maria, I., Mena, R., Binder, L. I., Avila, J., et al. (2008a). Cleavage and conformational changes of tau protein follow phosphorylation during Alzheimer's disease. Int. J. Exp. Pathol. 892, 81-90. doi: 10.1111/j.1365-2613.2007.00568.x

Mondragon-Rodriguez, S., Mena, R., Binder, L. I., Smith, M. A., Perry, G., and Garcia-Sierra, F. (2008b). Conformational changes and cleavage of tau in Pick bodies parallel the early processing of tau found in Alzheimer pathology. Neuropathol. Appl. Neurobiol. 341, 62-75.

Mondragon-Rodriguez, S., Perry, G., Luna-Munoz, J., Acevedo-Aquino, M. C., and Williams, S. (2014). Phosphorylation of tau protein at sites Ser(396-404) is one of the earliest events in Alzheimer's disease and Down syndrome. Neuropathol. Appl. Neurobiol. 402, 121-135. doi: 10.1111/nan.12084

Mondragon-Rodriguez, S., Perry, G., Zhu, X., and Boehm, J. (2012a). Amyloid Beta and tau proteins as therapeutic targets for Alzheimer's disease treatment: rethinking the current strategy. Int. J. Alzheimers Dis. 2012: 630182.

Mondragon-Rodriguez, S., Trillaud-Doppia, E., Dudilot, A., Bourgeois, C., Lauzon, M., Leclerc, N., et al. (2012b). Interaction of endogenous tau protein with synaptic proteins is regulated by $\mathrm{N}$-methyl-D-aspartate receptor-dependent tau phosphorylation. J. Biol. Chem. 28738, 32040-32053. doi: 10.1074/jbc.m112. 401240

Morris, M., Knudsen, G. M., Maeda, S., Trinidad, J. C., Ioanoviciu, A., Burlingame, A. L., et al. (2015). Tau post-translational modifications in wild-type and human amyloid precursor protein transgenic mice. Nat. Neurosci. 188, 1183-1189. doi: $10.1038 / \mathrm{nn} .4067$

Neve, R. L., Harris, P., Kosik, K. S., Kurnit, D. M., and Donlon, T. A. (1986). Identification of cDNA clones for the human microtubule-associated protein tau and chromosomal localization of the genes for tau and microtubuleassociated protein 2. Brain Res. 3873, 271-280. doi: 10.1016/0169-328x(86) 90033-1

Nicholls, S. B., DeVos, S. L., Commins, C., Nobuhara, C., Bennett, R. E., Corjuc, D. L., et al. (2017). Characterization of TauC3 antibody and demonstration of its potential to block tau propagation. PLoS One 125:e177914. doi: 10.1371/ journal.pone.0177914

Niewidok, B., Igaev, M., Sundermann, F., Janning, D., Bakota, L., and Brandt, R. (2016). Presence of a carboxy-terminal pseudorepeat and diseaselike pseudohyperphosphorylation critically influence tau's interaction with microtubules in axon-like processes. Mol. Biol. Cell 2722, 3537-3549. doi: 10.1091/mbc.e16-06-0402

Ondrejcak, T., Klyubin, I., Corbett, G. T., Fraser, G., Hong, W., Mably, A. J., et al. (2018). Cellular prion protein mediates the disruption of hippocampal 
synaptic plasticity by soluble tau in vivo. J. Neurosci. 3850, 10595-10606. doi: 10.1523/jneurosci.1700-18.2018

Paoletti, P., Bellone, C., and Zhou, Q. (2013). NMDA receptor subunit diversity: impact on receptor properties, synaptic plasticity and disease. Nat. Rev. Neurosci. 146, 383-400. doi: 10.1038/nrn3504

Patrick, G. N., Zukerberg, L., Nikolic, M., . de la Monte, S., Dikkes, P., and Tsai, L. H. (1999). Conversion of p35 to p 25 deregulates Cdk5 activity and promotes neurodegeneration. Nature 4026762, 615-622. doi: 10.1038/45159

Pinheiro, S., Silva, J., Mota, C., Vaz-Silva, J., Veloso, A., Pinto, V., et al. (2016). Tau mislocation in glucocorticoid-triggered hippocampal pathology. Mol. Neurobiol. 537, 4745-4753. doi: 10.1007/s12035-015-9356-2

Pooler, A. M., Noble, W., and Hanger, D. P. (2014). A role for tau at the synapse in Alzheimer's disease pathogenesis. Neuropharmacology $76 \mathrm{Pt} \mathrm{A:}, 1-8$. doi: 10.1016/j.neuropharm.2013.09.018

Pozueta, J., Lefort, R., Ribe, E. M., Troy, C. M., Arancio, O., and Shelanski, M. (2013). Caspase-2 is required for dendritic spine and behavioural alterations in J20 APP transgenic mice. Nat. Commun. 4:1939.

Regan, P., Piers, T., Yi, J. H., Kim, D. H., Huh, S., Park, S. J., et al. (2015). Tau phosphorylation at serine 396 residue is required for hippocampal LTD. J. Neurosci. 3512, 4804-4812. doi: 10.1523/jneurosci.2842-14.2015

Roberson, E. D., Halabisky, B., Yoo, J. W., Yao, J., Chin, J., Yan, F., et al. (2011). Amyloid-beta/Fyn-induced synaptic, network, and cognitive impairments depend on tau levels in multiple mouse models of Alzheimer's disease. J. Neurosci. 312, 700-711. doi: 10.1523/jneurosci.4152-10.2011

Roberson, E. D., Scearce-Levie, K., Palop, J. J., Yan, F. I, Cheng, H., Wu, T., et al. (2007). Reducing endogenous tau ameliorates amyloid beta-induced deficits in an Alzheimer's disease mouse model. Science 3165825, 750-754. doi: 10.1126/ science. 1141736

Rong, Y., Lu, X., Bernard, A., Khrestchatisky, M., and Baudry, M. (2001). Tyrosine phosphorylation of ionotropic glutamate receptors by Fyn or Src differentially modulates their susceptibility to calpain and enhances their binding to spectrin and PSD-95. J. Neurochem. 792, 382-390. doi: 10.1046/j.1471-4159.2001.00565.x

Sapir, T., Frotscher, M., Levy, T., Mandelkow, E. M., and Reiner, O. (2012). Tau's role in the developing brain: implications for intellectual disability. Hum. Mol. Genet. 218, 1681-1692. doi: 10.1093/hmg/ddr603

Scheff, S. W., Price, D. A., Schmitt, F. A., and Mufson, E. J. (2006). Hippocampal synaptic loss in early Alzheimer's disease and mild cognitive impairment. Neurobiol. Aging 2710, 1372-1384. doi: 10.1016/j.neurobiolaging.2005.09.012

Shentu, Y. P., Huo, Y., Feng, X. L., Gilbert, J., Zhang, Q., Liuyang, Z. Y., et al. (2018). CIP2A causes Tau/APP phosphorylation, synaptopathy, and memory deficits in alzheimer's disease. Cell Rep. 243, 713-723. doi: 10.1016/j.celrep.2018.06.009

Shipton, O. A., Leitz, J. R., Dworzak, J., Acton, C. E., Tunbridge, E. M., Denk, F., et al. (2011). Tau protein is required for amyloid \{beta\}-induced impairment of hippocampal long-term potentiation. J. Neurosci. 315, 1688-1692. doi: 10. 1523/jneurosci.2610-10.2011

Sohn, P. D., Tracy, T. E., Son, H. I., Zhou, Y., Leite, R. E., Miller, B. L., et al. (2016). Acetylated tau destabilizes the cytoskeleton in the axon initial segment and is mislocalized to the somatodendritic compartment. Mol. Neurodegener. 111:47.

Sokolow, S., Henkins, K. M., Bilousova, T., Gonzalez, B., Vinters, H. V., Miller, C. A., et al. (2015). Pre-synaptic C-terminal truncated tau is released from cortical synapses in Alzheimer's disease. J. Neurochem. 1333, 368-379. doi: 10.1111/jnc. 12991

Sotiropoulos, I., Catania, C., Pinto, L. G., Silva, R., Pollerberg, G. E., Takashima, A., et al. (2011). Stress acts cumulatively to precipitate Alzheimer's diseaselike tau pathology and cognitive deficits. J. Neurosci. 3121, 7840-7847. doi: 10.1523/jneurosci.0730-11.2011

Spires-Jones, T. L., and Hyman, B. T. (2014). The intersection of amyloid beta and tau at synapses in Alzheimer's disease. Neuron 824, 756-771. doi: 10.1016/j. neuron.2014.05.004

Stieler, J. T., Bullmann, T., Kohl, F., Toien, O., Bruckner, M. K., Hartig, W., et al. (2011). The physiological link between metabolic rate depression and tau phosphorylation in mammalian hibernation. PLoS One 61:e14530. doi: 10.1371/ journal.pone.0014530

Su, B., Wang, X., Drew, K. L., Perry, G., Smith, M. A., and Zhu, X. (2008). Physiological regulation of tau phosphorylation during hibernation. J. Neurochem. 1056, 2098-2108. doi: 10.1111/j.1471-4159.2008.05294.x
Swanson, E., Breckenridge, L., McMahon, L., Som, S., McConnell, I., and Bloom, G. S. (2017). Extracellular tau oligomers induce invasion of endogenous tau into the somatodendritic compartment and axonal transport dysfunction. J. Alzheimers Dis. 583, 803-820. doi: 10.3233/jad- 170168

Tackenberg, C., Grinschgl, S., Trutzel, A., Santuccione, A. C., Frey, M. C., Konietzko, U., et al. (2013). NMDA receptor subunit composition determines beta-amyloid-induced neurodegeneration and synaptic loss. Cell Death Dis. 4:e608. doi: 10.1038/cddis.2013.129

Tai, H. C., Serrano-Pozo, A., Hashimoto, T., Frosch, M. P., Spires-Jones, T. L., and Hyman, B. T. (2012). The synaptic accumulation of hyperphosphorylated tau oligomers in Alzheimer disease is associated with dysfunction of the ubiquitinproteasome system. Am. J. Pathol. 1814, 1426-1435. doi: 10.1016/j.ajpath.2012. 06.033

Tashiro, K., Hasegawa, M., Ihara, Y., and Iwatsubo, T. (1997). Somatodendritic localization of phosphorylated tau in neonatal and adult rat cerebral cortex. Neuroreport 812, 2797-2801. doi: 10.1097/00001756-199708180-00029

Terry, R. D., Masliah, E., Salmon, D. P., Butters, N., DeTeresa, R., Hill, R., et al. (1991). Physical basis of cognitive alterations in Alzheimer's disease: synapse loss is the major correlate of cognitive impairment. Ann. Neurol. 304, 572-580. doi: 10.1002/ana.410300410

Thies, E., and Mandelkow, E. M. (2007). Missorting of tau in neurons causes degeneration of synapses that can be rescued by the kinase MARK2/Par-1. J. Neurosci. 2711, 2896-2907. doi: 10.1523/jneurosci.4674-06.2007

Tracy, T. E., and Gan, L. (2017). Acetylated tau in Alzheimer's disease: an instigator of synaptic dysfunction underlying memory loss: increased levels of acetylated tau blocks the postsynaptic signaling required for plasticity and promotes memory deficits associated with tauopathy. Bioessays 39:1600224. doi: 10.1002/ bies.201600224

Tracy, T. E., Sohn, P. D., Minami, S. S., Wang, C., Min, S. W., Li, Y., et al. (2016). Acetylated tau obstructs KIBRA-mediated signaling in synaptic plasticity and promotes tauopathy-related memory loss. Neuron 902, 245-260. doi: 10.1016/ j.neuron.2016.03.005

Tsushima, H., Emanuele, M., Polenghi, A., Esposito, A., Vassalli, M., Barberis, A., et al. (2015). HDAC6 and RhoA are novel players in Abeta-driven disruption of neuronal polarity. Nat. Commun. 6:7781.

Weingarten, M. D., Lockwood, A. H., Hwo, S. Y., and Kirschner, M. W. (1975). A protein factor essential for microtubule assembly. Proc. Natl. Acad. Sci. U.S.A. 725, 1858-1862. doi: 10.1073/pnas.72.5.1858

Wu, H. Y., Kuo, P. C., Wang, Y. T., Lin, H. T., Roe, A. D., Wang, B. Y., et al. (2018). beta-amyloid induces pathology-related patterns of tau hyperphosphorylation at synaptic terminals. J. Neuropathol. Exp. Neurol. 779, 814-826. doi: 10.1093/ jnen/nly059

Xia, D., Gutmann, J. M., and Gotz, J. (2016). Mobility and subcellular localization of endogenous, gene-edited Tau differs from that of over-expressed human wild-type and P301L mutant Tau. Sci. Rep. 6:29074.

Xia, D., Li, C., and Gotz, J. (2015). Pseudophosphorylation of Tau at distinct epitopes or the presence of the P301L mutation targets the microtubuleassociated protein Tau to dendritic spines. Biochim. Biophys. Acta 18525, 913-924. doi: 10.1016/j.bbadis.2014.12.017

Yin, Y., Gao, D., Wang, Y., Wang, Z. H., Wang, X., Ye, J., et al. (2016). Tau accumulation induces synaptic impairment and memory deficit by calcineurinmediated inactivation of nuclear CaMKIV/CREB signaling. Proc. Natl. Acad. Sci. U.S.A. 11326, E3773-E3781.

Yuzwa, S. A., Shan, X., Macauley, M. S., Clark, T., Skorobogatko, Y., Vosseller, K., et al. (2012). Increasing O-GlcNAc slows neurodegeneration and stabilizes tau against aggregation. Nat. Chem. Biol. 84, 393-399. doi: 10.1038/nchembio.797

Zempel, H., Dennissen, F. J. A., Kumar, Y., Luedtke, J., Biernat, J., Mandelkow, E. M., et al. (2017). Axodendritic sorting and pathological missorting of Tau are isoform-specific and determined by axon initial segment architecture. J. Biol. Chem. 29229, 12192-12207. doi: 10.1074/jbc.m117.784702

Zempel, H., Luedtke, J., Kumar, Y., Biernat, J., Dawson, H., Mandelkow, E., et al. (2013). Amyloid-beta oligomers induce synaptic damage via Tau-dependent microtubule severing by TTLL6 and spastin. EMBO J. 3222, 2920-2937. doi: 10.1038/emboj.2013.207

Zempel, H., Thies, E., Mandelkow, E., and Mandelkow, E. M. (2010). Abeta oligomers cause localized $\mathrm{Ca}(2+)$ elevation, missorting of endogenous Tau into dendrites, Tau phosphorylation, and destruction of microtubules and spines. J. Neurosci. 3036, 11938-11950. doi: 10.1523/jneurosci.2357-10.2010 
Zhao, X., Kotilinek, L. A., Smith, B., Hlynialuk, C., Zahs, K., Ramsden, M., et al. (2016). Caspase-2 cleavage of tau reversibly impairs memory. Nat. Med. 2211, 1268-1276. doi: $10.1038 / \mathrm{nm} .4199$

Zhou, Q., Homma, K. J., and Poo, M. M. (2004). Shrinkage of dendritic spines associated with long-term depression of hippocampal synapses. Neuron 445, 749-757.

doi: 10.1016/j.neuron.2004.11.011

Zhou, Q., Xiao, M., and Nicoll, R. A. (2001). Contribution of cytoskeleton to the internalization of AMPA receptors. Proc. Natl. Acad. Sci. U.S.A. 983, 1261-1266. doi: $10.1073 /$ pnas.98.3.1261
Conflict of Interest: The authors declare that the research was conducted in the absence of any commercial or financial relationships that could be construed as a potential conflict of interest.

Copyright (๑ 2021 Yin, Zhao, Qiu, Zhou, Bao and Qian. This is an open-access article distributed under the terms of the Creative Commons Attribution License (CC BY). The use, distribution or reproduction in other forums is permitted, provided the original author(s) and the copyright owner(s) are credited and that the original publication in this journal is cited, in accordance with accepted academic practice. No use, distribution or reproduction is permitted which does not comply with these terms. 